\title{
Polymorphisms of the Genes Encoding CD40 and Growth Differentiation Factor 15 and in the 9p21.3 Region in Patients with Rheumatoid Arthritis and Cardiovascular Disease
}

\author{
LISBETH ÄRLESTIG and SOLBRITT RANTAPÄÄ-DAHLQVIST
}

\begin{abstract}
Objective. Genes or gene products associated with coronary artery disease in the general population were analyzed in rheumatoid arthritis (RA) patients with atherothrombotic manifestations (ATM).

Methods. A cross-sectional study of 681 individuals (498 women; 183 men) with RA (American College of Rheumatology criteria), a mean age of $60.6 \pm 13.2$ years, and mean disease duration of 15.5 \pm 12.6 years who were consecutively recruited and followed for 6 years. The prevalence of ATM [i.e., myocardial infarction, angina pectoris with intervention, deep vein thrombosis/pulmonary embolism (DVT/PE), and/or stroke/transient ischemic attack (TIA)] was recorded. Polymorphisms were analyzed in the genes coding for growth differentiation factor 15 (GDF15)/monocyte inhibitory cytokine-1 (MIC-1; rs1058587), CD40 (rs1535045 and rs3765459), and the 9p21.3 locus (rs1333049). Controls were randomly selected ( $\mathrm{n}=687$; matched for age and sex).

Results. The distribution of genotypes of GDF15/MIC-1 differed significantly between patients with RA and controls (chi-squared $=6.40,2 \mathrm{df}, \mathrm{p}=0.041$ ). ATM were associated with polymorphism of the GDF15/MIC-1 G allele (OR 2.21, 95\% CI 1.17-4.18), and with CC genotype of the 9p21.3 locus (rs1333049; OR 1.92, 95\% CI 1.15-3.19). Stroke/TIA in women was associated with GDF15/MIC-1 GG genotype (OR $3.75,95 \%$ CI 1.06-13.33), while stroke/TIA in men was associated with CD40 homozygous major alleles (OR 6.48, 95\% CI 1.31-32.0 and OR 2.78, 95\% CI 0.78-9.91, respectively). DVT/PE was associated with polymorphism in the GDF15/MIC-1 gene (rs1058587) minor allele (OR $3.53,95 \%$ CI $1.30-9.58$ ).

Conclusion. The gene polymorphisms analyzed were associated with different ATM in RA. The GDF15/MIC-1 gene polymorphism was also associated with RA per se, suggesting a common etiology for RA and ATM. (First Release April 15 2012; J Rheumatol 2012;39:939-45; doi:10.3899/ jrheum.111336)
\end{abstract}

Key Indexing Terms: RHEUMATOID ARTHRITIS GENE POLYMORPHISM

$\begin{array}{cr}\text { ATHEROTHROMBOTIC DISEASE } & \text { 9p21.3 LOCUS } \\ \text { GROWTH DIFFERENTIATION FACTOR 15 } & C D 40\end{array}$

An increased morbidity and mortality due to cardiovascular disease (CVD) among individuals with rheumatoid arthritis (RA) has been identified in several studies ${ }^{1,2,3}$. The etiological and pathogenic mechanisms are not well defined, but the inflammatory activity in patients with RA is important for the development of $\mathrm{CVD}^{4}$. Risk factors for CVD in patients with

From the Departments of Public Health and Clinical Medicine/Rheumatology, Umeå University, Umeå, Sweden.

Supported by grants from the Swedish Research Council

(K2010-52X-20307-04-3), the Swedish Rheumatism Association, the King Gustav Vth 80-year Foundation, and the Swedish COMBINE program.

L. Ärlestig, BSc; S. Rantapää-Dahlqvist, MD, PhD, Professor,

Departments of Public Health and Clinical Medicine/Rheumatology,

Umeå University.

Address correspondence to Dr. S. Rantapää-Dahlqvist,

Department of Public Health and Clinical Medicine, Rheumatology,

University Hospital, SE-901 85 Umeå, Sweden.

E-mail: solbritt.rantapaa.dahlqvist@medicin.umu.se

Full Release Article. For details see Reprints/Permissions at jrheum.org

Accepted for publication January 24, 2012.
RA show a pattern different from that of the general population $^{5,6}$ [with the exception of hypertension (HTN)], one that is highly prevalent in $\mathrm{RA}^{7}$. However, other traditional risk factors for CVD, such as age, being male, current smoking, and hypertriglyceridemia, have also been shown to affect CVD in patients with RA in prospective studies ${ }^{8}$.

In a previous study we reported an association between plasminogen activator inhibitor type 1 gene and ischemic heart disease (IHD) in patients with $\mathrm{RA}^{9}$. Several studies have shown an increased risk of a CV event and/or mortality in patients with RA carrying HLA-DRB1 shared-epitope alleles ${ }^{10,11,12,13}$. Further, associations have been shown between polymorphisms of the vasculature endothelial growth factor A gene $^{14}$, the interleukin 6 gene $^{15}$, the methylene tetrahydrofolate reductase gene ${ }^{16}$ and the tumor necrosis factor (TNF)-308 gene $^{17}$, and IHD, myocardial infarction (MI), and CVD, respectively. An association has been found between polymorphism in the lymphotoxin A gene and the risk of an $\mathrm{MI}^{18}$.

In our study of patients with RA, polymorphisms in genes

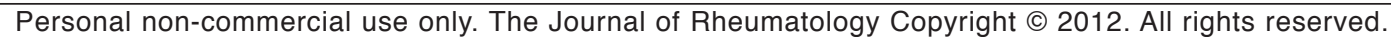


reported to be associated with manifestations of CVD in the general population were analyzed. Two of the genes, i.e., growth differentiation factor 15 (GDF15)/macrophage inhibitory cytokine $1(M I C-1)$ and $C D 40$, have been described as having proinflammatory properties. One single-nucleotide polymorphism (SNP), rs1333049, on chromosome 9p21.3 was identified in several genome-wide association studies to be associated with coronary heart disease in the general population $^{19,20,21,22}$. This association has been confirmed in a number of subsequent studies ${ }^{23}$ and has also been confirmed in the population from northern Sweden ${ }^{24}$.

GDF 15/MIC-1, a member of the transforming growth factor- $ß$ superfamily, was first described as being expressed by activated macrophages ${ }^{25}$. It is considered a regulator of macrophage activation and a target for $\mathrm{p} 53$, which is involved in the injury response to DNA damage ${ }^{26}$. Elevated serum concentrations of GDF15 were found in different types of CVD, such as angina pectoris, MI, coronary revascularization, heart failure, stroke, and in death from a cardiovascular event ${ }^{27,28}$. A polymorphism in exon 2 designated $H 6 D$, rs 1058587 , causes an amino acid change from histidine to aspartic acid. The D variant is not recognized by an antibody that is conformationdependent $^{29}$, suggesting that the protein conformation has altered and that it may function differently. High serum levels of GDF 15 and presence of the D allele were associated with an earlier onset of RA and were predictive of early erosive disease $\mathrm{e}^{30}$.

CD40 is a cell-surface receptor involved in immunoregulatory signaling when interacting with its ligand, CD40L. The receptor is expressed on $\mathrm{B}$ lymphocytes, fibroblasts, antigen-presenting cells, and endothelial and epithelial cells. The receptor is essential for $\mathrm{T}$ cell-dependent immunoglobulin class-switching and the development of memory B cells ${ }^{31}$. The analyzed polymorphisms, rs 1535045 and rs3765459, are located in the first and last introns and are both associated with less coronary artery calcification ${ }^{32}$.

In our study, the GDF15 (rs1058587), CD40 (rs1535045 and rs3765459), and 9p21.3 (rs1333049) polymorphisms were analyzed in patients with RA from northern Sweden in connection with the development of atherothrombotic disease.

\section{MATERIALS AND METHODS}

Study groups. Patients with RA (American College of Rheumatology criteria; $\mathrm{n}=723)^{33}$ from northern Sweden were consecutively included into the study during the first 4 months of 1995, 2000, 2001, and 2002. Of these, 681 patients (498 women and 183 men) donated blood samples for DNA analysis. A thorough survey of all the available patient records from onset of RA until inclusion in the study was performed retrospectively according to a structured registration form. All patients were followed prospectively from the inclusion date for 6 years.

Atherothrombotic manifestations (ATM) after the onset of RA were registered retrospectively according to the following definitions: an MI was diagnosed when changes on electrocardiograms, according to the Minnesota $\operatorname{code}^{34}$, were assessed by a clinical physiologist or cardiologist concurrent with the typical enzymatic pattern and/or verified on echocardiographic examination; IHD was included in addition to an MI when there was severe verified angina pectoris with coronary artery bypass graft surgery and percu- taneous coronary intervention; stroke was recorded when an intracerebral hemorrhage or infarction had been diagnosed following computerized tomography or magnetic resonance imaging, or when a typical clinical picture with neurological deficits had persisted for more than $24 \mathrm{~h}$; a transient ischemic attack (TIA) was recorded in those cases in which a focal neurological deficit of presumed ischemic origin had persisted for $<24 \mathrm{~h}$; deep vein thrombosis/pulmonary embolism (DVT/PE) was recorded when the diagnosis had been verified objectively (e.g., phlebography, sonography, scintigraphy, and/or arteriography) or when clinical signs combined with pulmonary radiography, electrocardiography, and laboratory changes resulted in fulltime treatment with warfarin. HTN was defined as treatment for it. At entry into the study, 83 patients had been affected, of whom 51 had been affected by IHD (an MI and/or angina pectoris with intervention), 26 by stroke/TIA, 12 by DVT/PE. Six of those patients had 2 of these ATM. Total accumulated disease activity was analyzed from retrospective data by calculation of the number of joints affected by arthritis, erythrocyte sedimentation rate $(\mathrm{mm} / \mathrm{h})$, and the physician's global assessment as described by Baecklund, et $a l^{35}$. Treatments ( $\geq 6$ months) with corticosteroids, diseasemodifying antirheumatic drugs (DMARD), anti-TNF treatment, and statins were registered.

The 6-year followup information was derived from the register of the National Board of Health in Sweden to obtain data on hospital inpatient care and/or death with a diagnosis of a new event, e.g., MI (ICD-10; I21.0-9, I22.0-1, I22.8-9.), angina pectoris with intervention (Z 951 or 955 or FNG V9250, 9251, 9253), and/or stroke/TIA (ICD-10; I61.0-6, I61.8-9, I62.9, I63.0-6, I63.8-9 and I64), and DVT/PE (I26, I80.2). These outcomes have been validated in another study with $96 \%$ concordance $^{36}$.

A population-based group of 696 individuals from the county of Västerbotten who were participating in the Northern Sweden World Health Organization Multinational Monitoring of Trends and Determinants in Cardiovascular Disease (WHO MONICA) project were identified in the Medical Biobank of Northern Sweden and used as controls. They were randomly selected on the basis of age (women $60 \pm 12$ years and men $64 \pm 10$ years) and sex (513 women and 183 men). Among the controls, $42 \%$ of the women and $50 \%$ of the men had a history of smoking, and $43 \%$ of the women and $17 \%$ of the men had HTN.

DNA extraction and assays. Genomic DNA was extracted from buffy-coat cells using standard methods. The 5'-nuclease allelic discrimination assays used for genotyping the polymorphisms rs1535045 and rs3765459 in the CD40 gene, rs1333049 at chromosome 9p21.3, and rs1058587 in GDF15 (C to $\mathrm{G}$; also designated as $H 6 D$ ) were supplied by Applied Biosystems (Foster City, CA, USA). The manufacturer's instructions were used for analyzing the SNP on an ABI Prism 7900HT sequence detector system (Applied Biosystems). For identification of the genotypes the SDS 2.1 software was used (Applied Biosystems).

Anticitrullinated protein antibodies (ACPA) were analyzed using an ELISA (cutoff value 5 units/ml) from Axis Shield Diagnostics (Dundee, UK). Rheumatoid factors (RF) of the IgM isotype were measured with an ELISA (cutoff value 20 units/ml) from ORG 522M (Orgentec Diagnostika GmbH, Mainz, Germany).

Statistics. The chi-squared test was used for testing categorical data between groups and logistic regression analyses were used to estimate OR for predicting variables for the dependent variable. For analysis of continuous data, the independent t-test was used. All $\mathrm{p}$ values are 2 -sided, and $\mathrm{p}$ values $\leq 0.05$ were considered statistically significant. Calculations were performed using SPSS 18.0 software (Chicago, IL, USA). Any adjustments in the multiple logistic analyses were chosen based on knowledge from previous studies. Selection of genes for analysis was based on a preformed hypothesis and no compensation was made for multiple testing.

Based on previously published frequencies of the genes, the power in our cohort to detect significant differences $(\mathrm{p}<0.05)$ for $9 \mathrm{p} 21.3$ types was $67 \%$ and for GDF15 polymorphisms was $70 \%$.

Linkage disequilibrium ( $D$ ' and $\mathrm{r}^{2}$ values) calculated for $C D 40$ SNP were derived using Haploview 4.2 software. 


\section{RESULTS}

Patients with an ATM were older, had a longer duration of disease, were more likely to be men, more often had nodules, and more often had HTN and diabetes (Table 1). They were more frequently treated with steroids, while methotrexate was less often chosen as their DMARD treatment. During the followup period, 149 new ATM were registered for 128 patients, defined as an MI, angina pectoris with intervention, stroke/TIA, and DVT/PE. Since the onset of RA, 195 ATM were recorded for 159 patients with RA, of whom 158 were genotyped. The different ATM stratified for sex are presented in Table 2. During the followup, 74 patients were treated with lipid-lowering drugs (statins). Thirty-five of those patients had an ATM $(\mathrm{p}<0.001)$ and 123 were treated with anti-TNF inhibitors. Seven treated with anti-TNF experienced an ATM, while 116 did not experience an ATM $(\mathrm{p}<0.01)$.

The distribution of the genotypes of all polymorphisms studied was in agreement with Hardy-Weinberg equilibrium for both controls and patients. Distribution of the genotypes of GDF 15 differed significantly between patients with RA and controls (chi-squared $=6.40,2 \mathrm{df}, \mathrm{p}=0.041$ ). The difference in genotype frequencies was more prominent among women (chi-squared $=12.19,2 \mathrm{df}, \mathrm{p}=0.002$ ). Carriage of the $\mathrm{G}$ type $(\mathrm{GG}+\mathrm{CG})$ was particularly increased among women (OR $1.50,95 \%$ CI $1.16-1.94, p=0.002)$. The minor allele, $\mathrm{G}$, was significantly more common among the patients than the controls: $31.4 \%$ versus $26.9 \%$ (OR 1.24, 95\% CI 1.04-1.48, p = $0.013)$. The frequency distribution of genotypes, carriers, and alleles did not differ between patients with RA and controls regarding the SNP rs1535045 and rs3765459 on the CD40 gene, and rs1333049 in 9p21.3.

Overall, an ATM was predicted for patients after the onset of RA by carriage of the GG genotype of rs1058587, suggesting a recessive model. The relationship was strengthened when adjusted for sex, shared epitope, ACPA, accumulated disease activity, HTN, diabetes mellitus, treatment with statins or anti-TNF inhibitors, a history of smoking, and age at the onset of RA (Table 3). Also, the rare genotype of 9p21.3 predicted ATM with an even higher OR after the defined adjustments fitting a recessive model (Table 3). Concerning 9p21.3, there was also a significant OR for ATM affecting the patients during the 6-year followup period (Table 3 ). The genotypes of 9p21.3 and GDF15/MIC-1 were not associated $(\mathrm{p}=0.198)$ but in a multiple logistic regression analysis including both types and the same adjustment as above, the OR for both increased (OR 2.16, 95\% CI 1.33-3.53 and OR 2.48, 95\% CI 1.35-4.54, respectively). Adjustments for RF instead of ACPA yielded similar results. IHD was significantly predicted only after adjustments based on homozygosity of the minor allele of 9p21.3 (OR 2.12, 95\% CI 1.11-4.05, p < 0.05).

Stratification for sex showed that the minor allele and genotypes GG and CG of GDF15 were also strongly related to stroke/TIA in female patients, for whom the GG genotype remained significant after the same adjustments as given above (Table 4). Testing for an additive model was significant (Cochrane-Armitage trend test, $\mathrm{p}=0.006$ ). Men homozygous for the major alleles, CC in rs1535045 and GG in rs3765459 (CD40), analyzed separately, were more often affected by

Table 1. Clinical and demographic data for study patients with rheumatoid arthritis (RA) stratified by atherothrombotic manifestation (ATM). Data are mean \pm SD or $\mathrm{n}(\%)$.

\begin{tabular}{lccc}
\hline Variable & All Patients & Patients without ATM & Patients with ATM \\
\hline Age, yrs & $60.6 \pm 13.2$ & $58.0 \pm 13.2$ & $68.9 \pm 9.2 * * *$ \\
Age at onset, yrs & $45.4 \pm 15.5$ & $43.7 \pm 14.9$ & $51.1 \pm 16.2^{* * *}$ \\
Disease duration, yrs & $15.5 \pm 12.6$ & $14.6 \pm 12.0$ & $18.3 \pm 14.1^{* *}$ \\
Women & $498(73.1)$ & $395(75.7) * *$ & $103(64.8)$ \\
Rheumatoid factor & $617 / 676(91.3)$ & $470 / 518(90.7)$ & $147 / 158(93.0)$ \\
ACPA & $522 / 645(80.9)$ & $407 / 504(80.8)$ & $115 / 141(81.6)$ \\
HLA-SE (0401/0404/0408) & $426 / 661(64.4)$ & $329 / 511(64.4)$ & $97 / 150(64.7)$ \\
Nodules & $217 / 678(32.0)$ & $151 / 519(29.1)$ & $66 / 159(41.5)^{* *}$ \\
Erosions & $543 / 666(81.5)$ & $414 / 513(80.7)$ & $129 / 153(84.3)$ \\
Accumulated disease activity* & $4.58 \pm 0.97$ & $4.56 \pm 0.97$ & $4.66 \pm 0.98$ \\
Ever smoked & $325 / 674(48.2)$ & $246 / 520(47.3)$ & $79 / 154(51.3)$ \\
Previous ATM ${ }^{\dagger}$ & $83 / 681(12.3)$ & - & $84 / 159(52.8)$ \\
Hypertension & $256 / 679(37.7)$ & $172 / 520(33.1)$ & $84 / 159(52.8)^{* * *}$ \\
Diabetes & $45 / 677(6.6)$ & $25 / 519(4.8)$ & $20 / 158(12.7)^{* *}$ \\
DMARD, ever & $622 / 678(91.7)$ & $479 / 520(92.1)$ & $143 / 158(90.5)$ \\
Methotrexate, ever & $411 / 678(60.6)$ & $330 / 520(63.5)^{* *}$ & $81 / 158(51.3)$ \\
Steroids, ever & $389 / 677(57.5)$ & $270 / 518(52.1)$ & $119 / 159(74.8)^{* * *}$ \\
Lipid-lowering drugs (statins) & $14 / 681(2.1)$ & $4 / 522(0.8)$ & $10 / 159(6.3)^{* * *}$ \\
Anti-TNF therapy & $27 / 681(4.0)$ & $27 / 522(5.2)^{* *}$ & $0 / 159(0)$
\end{tabular}

* Calculated according to Baecklund, et $a l^{35} . * * \mathrm{p}<0.01, * * * \mathrm{p}<0.001 .{ }^{\dagger}$ ATM defined as myocardial infarction, angina pectoris with intervention, stroke/transient ischemic attack, and deep-vein thrombosis/pulmonary embolism after onset of RA. ACPA: anticitrullinated protein antibodies; HLA-SE: HLA shared-epitope; DMARD: disease-modifying antirheumatic drug; TNF: tumor necrosis factor. 
Table 2. Number of atherothrombotic manifestations (ATM) in patients with rheumatoid arthritis (RA) after 6-year followup and overall after onset of RA.

\begin{tabular}{lcc}
\hline ATM Type & $\begin{array}{c}\text { Patients Affected After 6-Year } \\
\text { Followup, } \mathrm{n}=128(41 \mathrm{M} / 87 \mathrm{~F})\end{array}$ & $\begin{array}{c}\text { Patients with Manifestations } \\
\text { Overall, } \mathrm{n}=159(56 \mathrm{M} / 103 \mathrm{~F})\end{array}$ \\
\hline AMI, n (\%) & $59(8.7)$ & $85(12.5)$ \\
Men & $21(11.5)$ & $33(18.0)^{*}$ \\
Women & $38(7.6)$ & $52(10.4)$ \\
Angina pectoris with intervention, n (\%) & $24(3.5)$ & $24(3.5)$ \\
Men & $8(4.4)$ & $8(4.4)$ \\
Women & $16(3.2)$ & $16(3.2)$ \\
Stroke/TIA, n (\%) & $45(6.6)$ & $57(8.4)$ \\
Men & $16(8.7)$ & $21(11.5)$ \\
Women & $29(5.8)$ & $36(7.2)$ \\
DVT/PE, n $(\%)$ & $21(3.1)$ & $29(4.3)$ \\
Men & $4(2.2)$ & $7(3.8)$ \\
Women & $17(3.4)$ & $22(4.4)$ \\
Total, n & 149 & 195 \\
Men & 49 & $69^{*}$ \\
Women & 100 & 126 \\
\hline
\end{tabular}

$* \mathrm{p}<0.01$. AMI: acute myocardial infarction; TIA: transient ischemic attack; DVT: deep-vein thrombosis;

PE: pulmonary embolism.

Table 3. Frequency of atherothrombotic manifestation (ATM)* in patients with rheumatoid arthritis (RA) after disease onset stratified by GDF15 and rs1333049 on chromosome 9p21.3 single-nucleotide polymorphism (SNP) genotypes. All analyses adjusted for sex, shared-epitope, accumulated disease activity, ACPA, hypertension, diabetes mellitus, ever-smoker, treatment with statins and anti-TNF inhibitor, and age at disease onset.

\begin{tabular}{|c|c|c|c|c|c|c|c|c|}
\hline \multirow[b]{2}{*}{ Genes/SNP } & \multicolumn{4}{|c|}{ ATM After RA Onset } & \multicolumn{4}{|c|}{ ATM at 6-year Followup } \\
\hline & Negative & $\begin{array}{l}\text { Positive, } \\
\text { n (\%) }\end{array}$ & $\begin{array}{c}\text { OR (95\% CI), } \\
\text { Unadjusted }\end{array}$ & $\begin{array}{l}\text { OR }(95 \% \mathrm{CI}), \\
\text { Adjusted }\end{array}$ & Negative & $\begin{array}{l}\text { Positive, } \\
\text { n (\%) }\end{array}$ & $\begin{array}{c}\text { OR (95\% CI), } \\
\text { Unadjusted }\end{array}$ & $\begin{array}{l}\text { OR }(95 \% \mathrm{CI}) \\
\text { Adjusted }\end{array}$ \\
\hline \multicolumn{9}{|l|}{ GDF 15 rs 1058587} \\
\hline $\mathrm{CC}$ & 251 & $69(21.6)$ & 1.0 (referent) & & 264 & $56(17.5)$ & 1.0 (referent) & \\
\hline $\mathrm{CG}$ & 227 & $66(22.5)$ & $1.06(0.72-1.55)$ & $0.93(0.59-1.48)$ & 237 & $56(19.1)$ & $1.11(0.74-1.68)$ & $0.92(0.56-1.51)$ \\
\hline GG & 44 & $23(34.3)$ & $1.90(1.08-3.36)$ & $2.14(1.09-4.19)$ & 51 & $16(23.9)$ & $1.48(0.79-2.78)$ & $1.43(0.67-3.04)$ \\
\hline \multicolumn{9}{|c|}{9 p21.3 rs1333049 } \\
\hline GG & 163 & $49(23.1)$ & 1.0 (referent) & & 175 & $37(17.5)$ & 1.0 (referent) & \\
\hline CG & 264 & $71(21.2)$ & $0.90(0.59-1.35)$ & $0.90(0.55-1.47)$ & 277 & $58(17.3)$ & $0.99(0.63-1.56)$ & $1.16(0.66-2.04)$ \\
\hline $\mathrm{CC}$ & 83 & $38(31.4)$ & $1.52(0.92-2.51)$ & $1.80(1.00-3.24)$ & 89 & $32(26.4)$ & $1.70(0.99-2.91)$ & $2.46(1.29-4.70)$ \\
\hline $\mathrm{CC}$ vs $\mathrm{GG}+\mathrm{CG}$ & 83 & $38(31.4)$ & $1.63(1.06-2.51)$ & $1.92(1.15-3.19)$ & 89 & $32(26.4)$ & $1.71(1.08-2.71)$ & $2.24(1.30-3.87)$ \\
\hline
\end{tabular}

* ATM defined as myocardial infarction, angina pectoris with intervention, stroke/transient ischemic attack, and deep-vein thrombosis/pulmonary embolism. ACPA: anticitrullinated protein antibodies; TNF: tumor necrosis factor.

stroke (Table 4). After adjustments, the OR of rs1535045, both CC and C-allele, increased further, while the OR for the homozygosity of the rs3765459 allele turned nonsignificant (Table 4). Adjustment for RF instead of ACPA yielded similar results, but for the genotypes GG $+\mathrm{GC}$ versus $\mathrm{CC}$ of GDF15, a significant OR $(3.10,95 \%$ CI 1.22-7.87) was achieved. Twenty-nine patients had experienced DVT/PE, a finding that was predicted by carriage of the minor allele and the GG genotype of rs1058587 in GDF15, which was further strengthened by the mentioned adjustments (Table 5). Adjusting for RF instead of ACPA did not change the results. The association of the genotypes fit both a recessive and an additive model (Cochrane-Armitage trend test, $\mathrm{p}=0.024$ ).
Analysis of gene and smoking interaction gave an increased relative risk of stroke among women who smoked and carried the GDF15 GG genotype, compared with nonsmokers who did not have this genotype (OR 4.99, 95\% CI 1.37-18.20). Also, there was a small increase in the relative risk of ATM for those who smoked and carried the 9p21.3 CC genotype, compared with being a nonsmoker and not having this genotype (OR 2.35, 95\% CI 1.25-4.41).

\section{DISCUSSION}

In a number of previous studies of gene polymorphisms in patients with RA who had CVD, the choice of genes for analysis was based on a relationship with RA per se or with inflam- 
Table 4. Frequency and OR (95\% CI) of GDF15 and CD40 single-nucleotide polymorphism (SNP) genotypes stratified by sex in patients with rheumatoid arthritis (RA) and stroke/transient ischemic attack after onset of RA.

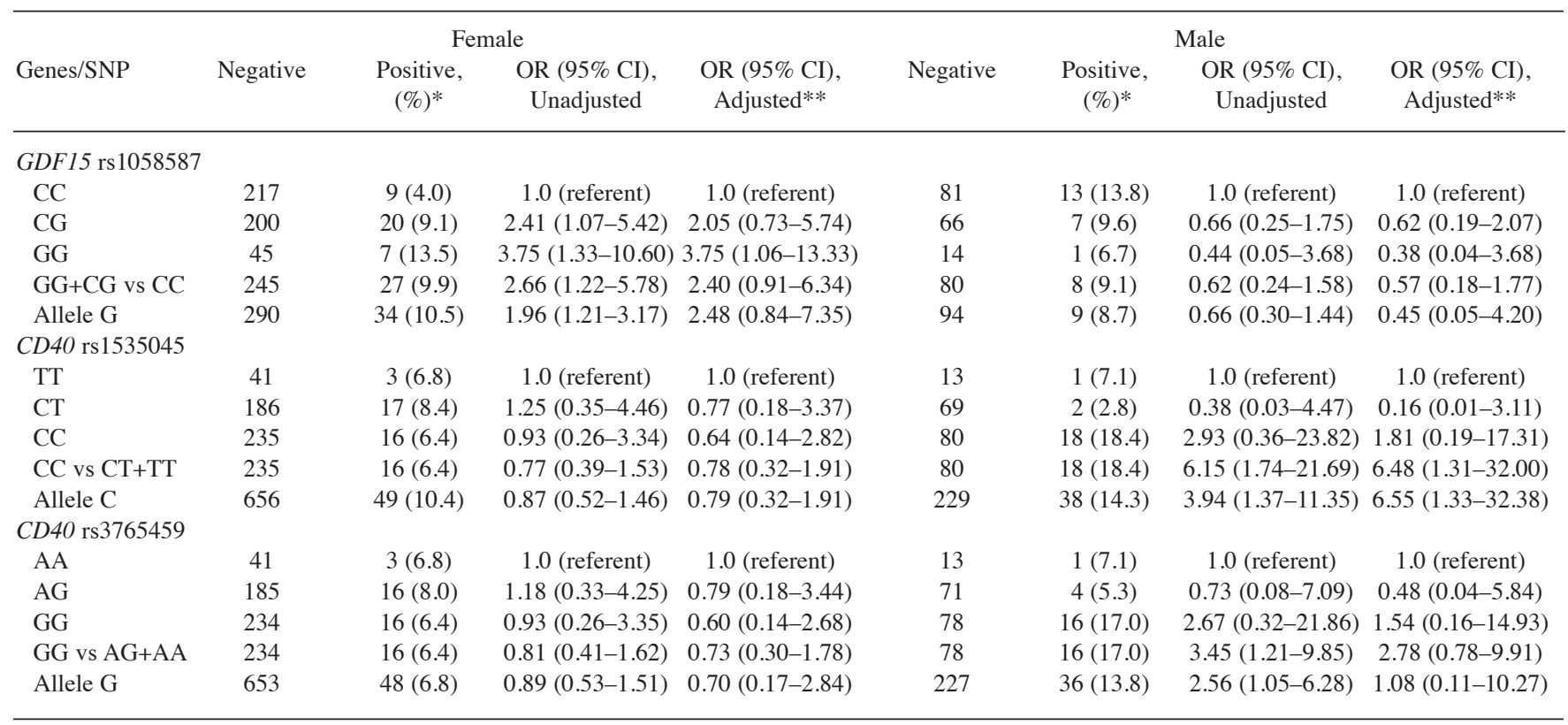

* Percentage of all patients with a given type. ** All analyses adjusted for shared-epitope, accumulated disease activity, ACPA, hypertension, diabetes mellitus, treatment with statins and anti-TNF inhibitors, ever-smoker, and age at onset. ACPA: anticitrullinated protein antibodies; TNF: tumor necrosis factor.

Table 5. Frequency of deep-vein thrombosis and pulmonary embolism in patients with rheumatoid arthritis stratified by GDF15 SNP genotypes. All analyses adjusted for sex, shared-epitope, accumulated disease activity, ACPA, hypertension, diabetes mellitus, ever-smoker, treatment with statins and anti-TNF inhibitor, and age at onset.

\begin{tabular}{|c|c|c|c|c|}
\hline Genes/SNP & Negative & Positive, $\mathrm{n}(\%)^{*}$ & $\begin{array}{c}\text { OR }(95 \% \mathrm{CI}) \text {, } \\
\text { Unadjusted }\end{array}$ & $\begin{array}{c}\text { OR }(95 \% \mathrm{CI}) \\
\text { Adjusted }\end{array}$ \\
\hline \multicolumn{5}{|l|}{ GDF 15 rs 1058587} \\
\hline $\mathrm{CC}$ & 311 & $9(2.8)$ & 1.0 (referent) & \\
\hline CG & 279 & $14(4.8)$ & $1.73(0.74-4.07)$ & $1.02(0.38-2.72)$ \\
\hline GG & 61 & $6(9.0)$ & $3.40(1.17-9.90)$ & $3.32(1.08-10.20)$ \\
\hline $\mathrm{GG}$ vs $\mathrm{CG}+\mathrm{CC}$ & 61 & $6(9.0)$ & $2.52(0.99-6.44)$ & $3.29(1.19-9.10)$ \\
\hline Allele G & 401 & $26(6.1)$ & $1.83(1.07-3.10)$ & $3.29(1.19-9.09)$ \\
\hline
\end{tabular}

* Percentage of all patients with a given type. ACPA: anticitrullinated protein antibodies; SNP: single-nucleotide polymorphism; TNF: tumor necrosis factor.

mation $^{37}$. However, in our study we have analyzed some of the genetic factors already shown to be of importance for CVD in the general population, i.e., polymorphisms in the gene encoding $C D 40$ and 9p21.3. The polymorphism $H 6 D$ in GDF15 has not previously been shown to be important for CVD events, but serum levels of GDF15 were related to CVD in the general population ${ }^{27,28}$ and in patients with $\mathrm{RA}^{30}$. Both CD40 and GDF15/MIC-1 have immunoregulatory properties $^{25,31,38}$. In the patients with RA, we were able to confirm associations with these selected SNP and CVD. The SNP rs1333049 on chromosome 9p21.3 was found, overall, to be associated with ATM, and ATM developed during the 6-year followup period. When the data were stratified for the differ- ent ATM, there was an association with IHD but we were unable to show a significant association for stroke, as reported by others ${ }^{24,39}$. Clearly this could be explained by a lack of statistical power due to too few individuals in our study.

Increased levels of GDF15/MIC-1 have been reported in several studies related to CVD or CV events, particularly in women $^{27,40,41}$. A number of SNP have been analyzed for the GDF15/MIC-1 gene, and in particular SNP associated with promoter activity were associated with GDF15 protein level. In most other published studies concerning CVD, the other SNP (i.e., rs4808793, rs1059369) on the gene have been analyzed and in the general population a relationship between rs1058587 $(+2438 \mathrm{C} / \mathrm{G})$ was not actually confirmed ${ }^{42}$.

Personal non-commercial use only. The Journal of Rheumatology Copyright @ 
However, in a study by Brown, et al this SNP was related to RA and particularly to erosive disease, suggesting a relationship with $\mathrm{RA}^{30}$. In our study we also found a strong relationship between RA per se and this SNP. The OR was, however, higher in comparison to the presence of an ATM and stroke/TIA, respectively, compared with any association with RA. The statistical significance remained after adjusting for sex and disease activity variables.

To our knowledge there is no report on an association between GDF15/MIC-1 and DVT or PE. The number of individuals with DVT/PE was small, consequently the data must be interpreted with care.

Elevated levels of the soluble ligand for CD40 (CD40L) have been found to be a risk marker for the development of cardiac events ${ }^{43}$. It was shown that those individuals at risk for CVD who were homozygous for the minor allele of either CD40 SNP (rs1535045 and rs3765459) had a significantly reduced coronary artery calcium score compared with carriers of the more frequent allele ${ }^{32}$. However, in our study the number of patients with minor allele was low, particularly when the patients were stratified for sex, consequently calculations on the minor alleles were not relevant. The major alleles of both SNP were found to be associated with an increased risk for stroke/TIA in men. This was not at all the case for women. We conclude that our results are in concordance with those from the study by Burdon, et $a l^{32}$. However, our data also indicated that rs1535045 was the true associated SNP with the significant associations, in both unadjusted and adjusted analyses, while the significance level was lower for rs3765459, and the 2 SNP are in strong linkage disequilibrium: $D^{\prime}=0.96$ and $\mathrm{r}^{2}=0.92$.

Differences between the sexes were found in the association analyses between gene polymorphisms and different ATM. However, the number of men $(\mathrm{n}=183)$ in our study was almost a third the number of women $(n=498)$, making it more difficult to show associations. Nevertheless, the OR concerning stroke was particularly high for men. Sex differences in terms of genetic risk factors for CVD have been described in a number of studies ${ }^{44}$.

During the followup, patients without ATM had been treated with anti-TNF significantly more often. However, the design of our study does not allow us to conclude that they were protected from ATM by anti-TNF therapy. This situation could be confounded by not introducing treatment with anti-TNF to patients at risk of an ATM. Our previous publication did not find less CVD in patients treated with anti-TNF ${ }^{45}$. Treatment with statins could be a "pseudomarker" for hyperlipidemia, which would be related to the observed increased frequency of ATM.

We were also able to identify an interaction between the GDF15 G allele and the 9p21.3 rs1333049 CC genotype and smoking, with an increase of OR for stroke and ATM, respectively. Smoking is a well known risk factor for CVD in the general population but only a few studies have reported obvi- ous harm from smoking in RA. This finding is probably not due to smoking being less harmful in patients with RA, but to its relatively small contribution to the total cardiovascular risk in these patients.

We were able to confirm the same associations between gene polymorphisms and CVD in patients with RA as have been described for the general population. However, we were also able to show that 1 of the gene polymorphisms was related to RA per se, thereby suggesting a common etiological background for RA and CVD.

\section{ACKNOWLEDGMENT}

The Northern Sweden WHO MONICA study group is acknowledged for help with the controls. We also thank Eleonor Blind for her laboratory work.

\section{REFERENCES}

1. Wallberg-Jonsson S, Ohman ML, Dahlqvist SR. Cardiovascular morbidity and mortality in patients with seropositive rheumatoid arthritis in Northern Sweden. J Rheumatol 1997;24:445-51.

2. Solomon DH, Karlson EW, Rimm EB, Cannuscio CC, Mandl LA, Manson JE, et al. Cardiovascular morbidity and mortality in women diagnosed with rheumatoid arthritis. Circulation 2003;107:1303-7.

3. Maradit-Kremers H, Crowson CS, Nicola PJ, Ballman KV, Roger VL, Jacobsen SJ, et al. Increased unrecognized coronary heart disease and sudden deaths in rheumatoid arthritis: A population-based cohort study. Arthritis Rheum 2005;52:402-11.

4. Wallberg-Jonsson S, Johansson H, Ohman ML, Rantapaa-Dahlqvist $\mathrm{S}$. Extent of inflammation predicts cardiovascular disease and overall mortality in seropositive rheumatoid arthritis. A retrospective cohort study from disease onset. J Rheumatol 1999;26:2562-71.

5. Gonzalez A, Maradit-Kremers H, Crowson CS, Ballman KV, Roger VL, Jacobsen SJ, et al. Do cardiovascular risk factors confer the same risk for cardiovascular outcomes in rheumatoid arthritis patients as in non-rheumatoid arthritis patients? Ann Rheum Dis 2008;67:64-9.

6. del Rincon ID, Williams K, Stern MP, Freeman GL, Escalante A. High incidence of cardiovascular events in a rheumatoid arthritis cohort not explained by traditional cardiac risk factors. Arthritis Rheum 2001;44:2737-45.

7. Panoulas VF, Metsios GS, Pace AV, John H, Treharne GJ, Banks $\mathrm{MJ}$, et al. Hypertension in rheumatoid arthritis. Rheumatology 2008;47:1286-98.

8. Innala L, Moller B, Ljung L, Magnusson S, Smedby T, Sodergren $\mathrm{A}$, et al. Cardiovascular events in early RA are a result of inflammatory burden and traditional risk factors: A five year prospective study. Arthritis Res Ther 2011;13:R131.

9. Arlestig L, Wallberg-Jonsson S, Stegmayr B, Rantapaa-Dahlqvist S. Polymorphism of genes related to cardiovascular disease in patients with rheumatoid arthritis. Clin Exp Rheumatol 2007;25:866-71.

10. Gonzalez-Gay MA, Gonzalez-Juanatey C, Lopez-Diaz MJ, Pineiro A, Garcia-Porrua C, Miranda-Filloy JA, et al. HLA-DRB1 and persistent chronic inflammation contribute to cardiovascular events and cardiovascular mortality in patients with rheumatoid arthritis. Arthritis Rheum 2007;57:125-32.

11. Mattey DL, Thomson W, Ollier WE, Batley M, Davies PG, Gough AK, et al. Association of DRB1 shared epitope genotypes with early mortality in rheumatoid arthritis: Results of eighteen years of followup from the early rheumatoid arthritis study. Arthritis Rheum 2007;56:1408-16.

12. Farragher TM, Goodson NJ, Naseem H, Silman AJ, Thomson W, 
Symmons D, et al. Association of the HLA-DRB1 gene with premature death, particularly from cardiovascular disease, in patients with rheumatoid arthritis and inflammatory polyarthritis. Arthritis Rheum 2008;58:359-69.

13. Gonzalez-Juanatey C, Testa A, Garcia-Castelo A, Garcia-Porrua C, Llorca J, Vidan J, et al. HLA-DRB1 status affects endothelial function in treated patients with rheumatoid arthritis. Am J Med 2003;114:647-52.

14. Chen Y, Dawes PT, Packham JC, Mattey DL. Interaction between smoking and polymorphism in the promoter region of the VEGFA gene is associated with ischemic heart disease and myocardial infarction in rheumatoid arthritis. J Rheumatol 2011;38:802-9.

15. Palomino-Morales R, Gonzalez-Juanatey C, Vazquez-Rodriguez TR, Miranda-Filloy JA, Llorca J, Martin J, et al. Interleukin-6 gene -174 promoter polymorphism is associated with endothelial dysfunction but not with disease susceptibility in patients with rheumatoid arthritis. Clin Exp Rheumatol 2009;27:964-70.

16. Palomino-Morales R, Gonzalez-Juanatey C, Vazquez-Rodriguez TR, Rodriguez L, Miranda-Filloy JA, Fernandez-Gutierrez B, et al. A1298C polymorphism in the MTHFR gene predisposes to cardiovascular risk in rheumatoid arthritis. Arthritis Res Ther 2010;12:R71.

17. Rodriguez-Rodriguez L, Gonzalez-Juanatey C, Palomino-Morales R, Vazquez-Rodriguez TR, Miranda-Filloy JA, Fernandez-Gutierrez $\mathrm{B}$, et al. TNFA -308 (rs1800629) polymorphism is associated with a higher risk of cardiovascular disease in patients with rheumatoid arthritis. Atherosclerosis 2011;216:125-30.

18. Panoulas VF, Nikas SN, Smith JP, Douglas KM, Nightingale P, Milionis HJ, et al. Lymphotoxin 252A $>\mathrm{G}$ polymorphism is common and associates with myocardial infarction in patients with rheumatoid arthritis. Ann Rheum Dis 2008;67:1550-6.

19. McPherson R, Pertsemlidis A, Kavaslar N, Stewart A, Roberts R, Cox DR, et al. A common allele on chromosome 9 associated with coronary heart disease. Science 2007;316:1488-91.

20. Wellcome Trust Case Control Consortium. Genome-wide association study of 14,000 cases of seven common diseases and 3,000 shared controls. Nature 2007;447:661-78.

21. Helgadottir A, Thorleifsson G, Manolescu A, Gretarsdottir S, Blondal T, Jonasdottir A, et al. A common variant on chromosome 9 p21 affects the risk of myocardial infarction. Science 2007;316:1491-3.

22. Samani NJ, Erdmann J, Hall AS, Hengstenberg C, Mangino M, Mayer B, et al. Genomewide association analysis of coronary artery disease. N Engl J Med 2007;357:443-53.

23. Schunkert H, Gotz A, Braund P, McGinnis R, Tregouet DA, Mangino $\mathrm{M}$, et al. Repeated replication and a prospective meta-analysis of the association between chromosome 9p21.3 and coronary artery disease. Circulation 2008;117:1675-84.

24. Karvanen J, Silander K, Kee F, Tiret L, Salomaa V, Kuulasmaa K, et al. The impact of newly identified loci on coronary heart disease, stroke and total mortality in the MORGAM prospective cohorts. Genet Epidemiol 2009;33:237-46.

25. Bootcov MR, Bauskin AR, Valenzuela SM, Moore AG, Bansal M, He XY, et al. MIC-1, a novel macrophage inhibitory cytokine, is a divergent member of the TGF-beta superfamily. Proc Natl Acad Sci USA 1997;94:11514-9.

26. Yang H, Filipovic Z, Brown D, Breit SN, Vassilev LT. Macrophage inhibitory cytokine-1: A novel biomarker for p53 pathway activation. Mol Cancer Ther 2003;2:1023-9.

27. Brown DA, Breit SN, Buring J, Fairlie WD, Bauskin AR, Liu T, et al. Concentration in plasma of macrophage inhibitory cytokine-1 and risk of cardiovascular events in women: A nested case-control study. Lancet 2002;359:2159-63.

28. Lind L, Wallentin L, Kempf T, Tapken H, Quint A, Lindahl B, et al. Growth-differentiation factor-15 is an independent marker of cardiovascular dysfunction and disease in the elderly: Results from the Prospective Investigation of the Vasculature in Uppsala Seniors (PIVUS) Study. Eur Heart J 2009;30:2346-53.

29. Fairlie WD, Russell PK, Wu WM, Moore AG, Zhang HP, Brown $\mathrm{PK}$, et al. Epitope mapping of the transforming growth factor-beta superfamily protein, macrophage inhibitory cytokine-1 (MIC-1): Identification of at least five distinct epitope specificities. Biochemistry 2001;40:65-73.

30. Brown DA, Moore J, Johnen H, Smeets TJ, Bauskin AR, Kuffner T, et al. Serum macrophage inhibitory cytokine 1 in rheumatoid arthritis: A potential marker of erosive joint destruction. Arthritis Rheum 2007;56:753-64.

31. van Kooten C, Banchereau J. CD40-CD40 ligand. J Leukoc Biol 2000;67:2-17.

32. Burdon KP, Langefeld CD, Beck SR, Wagenknecht LE, Carr JJ, Rich SS, et al. Variants of the CD40 gene but not of the CD40L gene are associated with coronary artery calcification in the Diabetes Heart Study (DHS). Am Heart J 2006;151:706-11.

33. Arnett FC, Edworthy SM, Bloch DA, McShane DJ, Fries JF, Cooper NS, et al. The American Rheumatism Association 1987 revised criteria for the classification of rheumatoid arthritis. Arthritis Rheum 1988;31:315-24.

34. Prineas RJ, Blackburn H. The Minnesota code manual of electrocardiographic findings: standards and procedures for measurement and classification. Boston: John Wright \& Son Ltd.; 1982.

35. Baecklund E, Sundstrom C, Ekbom A, Catrina AI, Biberfeld P, Feltelius N, et al. Lymphoma subtypes in patients with rheumatoid arthritis: Increased proportion of diffuse large B cell lymphoma. Arthritis Rheum 2003;48:1543-50.

36. Bengtsson C, Öhman ML, Nived O, Rantapää-Dahlqvist S. Cardiovascular event in systemic lupus erythematosus in northern Sweden - Incidence and predictors in a 7-year follow up study. Lupus 2011 Nov 7. [E-pub ahead of print]

37. Palomino-Morales R, Gonzalez-Juanatey C, Vazquez-Rodriguez TR, Rodriguez L, Miranda-Filloy JA, Pascual-Salcedo D, et al. Lack of association of PTPN22, STAT4 and TRAF1/C5 gene polymorphisms with cardiovascular risk in rheumatoid arthritis. Clin Exp Rheumatol 2010;28:695-701.

38. Pamukcu B, Lip GY, Snezhitskiy V, Shantsila E. The CD40-CD40L system in cardiovascular disease. Ann Med 2011;43:331-40.

39. Smith JG, Melander O, Lovkvist H, Hedblad B, Engstrom G, Nilsson P, et al. Common genetic variants on chromosome 9p21 confers risk of ischemic stroke: A large-scale genetic association study. Circ Cardiovasc Genet 2009;2:159-64.

40. Kempf T, Bjorklund E, Olofsson S, Lindahl B, Allhoff T, Peter T, et al. Growth-differentiation factor-15 improves risk stratification in ST-segment elevation myocardial infarction. Eur Heart J 2007;28:2858-65.

41. Khan SQ, Ng K, Dhillon O, Kelly D, Quinn P, Squire IB, et al. Growth differentiation factor-15 as a prognostic marker in patients with acute myocardial infarction. Eur Heart J 2009;30:1057-65.

42. Wang X, Yang X, Sun K, Chen J, Song X, Wang H, et al. The haplotype of the growth-differentiation factor 15 gene is associated with left ventricular hypertrophy in human essential hypertension. Clin Sci (Lond) 2010;118:137-45.

43. Schonbeck U, Varo N, Libby P, Buring J, Ridker PM. Soluble CD40L and cardiovascular risk in women. Circulation 2001;104:2266-8.

44. Silander K, Alanne M, Kristiansson K, Saarela O, Ripatti S, Auro $\mathrm{K}$, et al. Gender differences in genetic risk profiles for cardiovascular disease. PLoS One 2008;3:e3615.

45. Ljung L, Simard JF, Jacobsson L, Rantapaa-Dahlqvist S, Askling J; Anti-Rheumatic Therapy in Sweden (ARTIS) Study Group. Treatment with tumour necrosis factor-inhibitors and the risk of acute coronary syndromes in early rheumatoid arthritis. Arthritis Rheum 2012;64:42-52. 